\title{
A six year appraisal of caesarean delivery at a teaching hospital in Uttarakhand
}

\author{
Namrata Saxena*, Bhawna Sharma, Vineeta Gupta, Kamal S. Negi
}

Department of Obstetrics and Gynaecology, SGRRIM and HS, Dehradun, Uttarakhand, India

Received: 29 September 2016

Accepted: 24 October 2016

\section{*Correspondence:}

Dr. Namrata Saxena,

E-mail: msnamrata30@gmail.com

Copyright: () the author(s), publisher and licensee Medip Academy. This is an open-access article distributed under the terms of the Creative Commons Attribution Non-Commercial License, which permits unrestricted non-commercial use, distribution, and reproduction in any medium, provided the original work is properly cited.

\section{ABSTRACT}

Background: Caesarean section is one of the commonest surgical procedures worldwide. Its upward trend and its indications in low resource setting makes regular appraisal of the practice necessary.

Methods: A retrospective study. Labour ward logbook and case records were looked into, and all information extracted.

Results: The prevalence of caesarean section in the study population was $32.18 \%$. The most common indication of caesarean section was previous caesarean section (33\%) followed by fetal distress $(26.2 \%)$.

Conclusions: Risk appraisal and all efforts must be geared towards reducing caesarean section rate. Certain measures have been recommended.

Keywords: Caesarean section, Indications, Trends

\section{INTRODUCTION}

Pregnancy and delivery are considered as normal physiological phenomenon in women. Approximately, $10 \%$ deliveries are considered as high risk, some of which may require caesarean section. Caesarean delivery is potentially lifesaving obstetric surgery when properly performed and following appropriate medical indications ${ }^{1}$ The indications, however, vary widely from country to country, although the heterogeneity in classifications does not allow for valid comparisons. ${ }^{2}$ Increasing caesarean section rate is an issue of public health concern globally for last 30 years; its use has increased since 1970 to a level that is medically unjustified. Thus bringing negative, economic and health related repercussion. ${ }^{3}$

The World Health Organization (WHO) recommends that caesarean delivery rate (CDR) should not exceed $15 \%{ }^{4}$ Most estimated prevalence rate is $33 \%$, ranges from $4 \%$ in Africa to $29 \%$ in Latin America and Caribbean. ${ }^{5}$
In developed countries, attributed factors include fear of litigation, liberal use of caesarean section for breech presentation, detection of fetal distress by continuous electronic fetal monitoring among others. ${ }^{6}$ While reasons are less clear in developing countries which include specialist and referral nature of the hospital, unbooked status of most of the patients, increasing use of fetal rate abnormality alone as a measure of fetal distress, over diagnosis of cephalo-pelvic disproportion by junior doctors and use of caesarean section for patients with previous caesarean section.

Safety of caesarean section has improved over the decades due to improved anesthetic techniques which has accounted for rate increase across the world. ${ }^{8,9}$ This study aims to determine six year and annual caesarean delivery rate (CDR) in a teaching hospital in Uttarakhand, and to assess the indications. Conclusions will be drawn and recommendations made based on findings. 


\section{METHODS}

The study was carried out in the Obstetrics and Gynaecology department of the Shri Guru Ram Rai Institute of Medical and Health Science, Dehradun, Uttarakhand. It was a retrospective study from January 1, 2010 to December 31, 2015. Medical records from both central and labour ward were examined. Sociodemographic and other information were obtained. Statistical analysis was done with SPSS version 15 . Chisquare test was used to determine the level of significance. Level of significance was set at P-value $<0.05$. Univalent and multivariate analysis was done to obtain simple percentages and inferential statistics.

The study was approved by the hospital's research and ethics committee.

\section{RESULTS}

Of 8,413 deliveries during 6 year study period, 2,707 were caesarean deliveries, giving a CDR of $2,707 / 8,413$ $(32.18 \%)$.

Table 1 shows the trends in CDR. In 2010, CDR was $322 / 876$ (36.8\%), then dropped to $289 / 1014$ (28.5\%) in2012, increased again to $692 / 1977(35 \%)$ in 2014 , dropped again to $736 / 2345(31.4 \%)$ in 2015 .

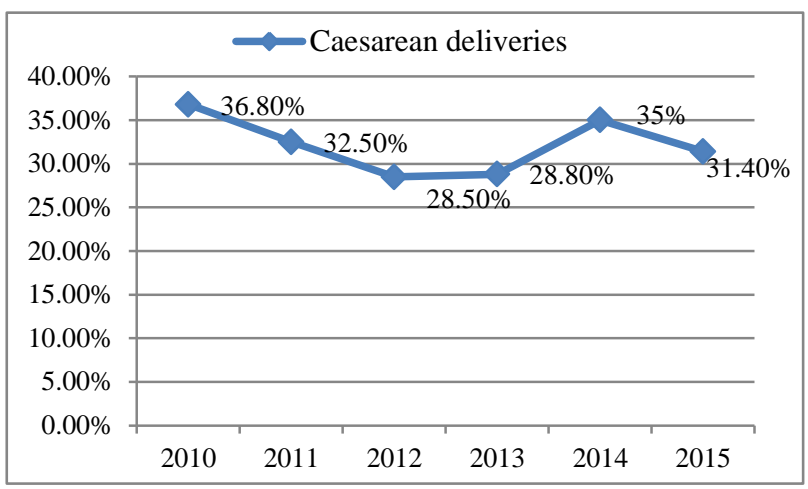

Figure 1: Annual caesarean delivery rate over a 6year period 2010-2015.

Table 1: Trend of caesarean delivery over a 6-year period 2010-2015.

\begin{tabular}{|lll|}
\hline Years & $\begin{array}{l}\text { Total } \\
\text { deliveries }\end{array}$ & $\begin{array}{l}\text { Number of caesarean } \\
\text { deliveries }(\%)\end{array}$ \\
\hline 2010 & 876 & $322(36.8 \%)$ \\
\hline 2011 & 892 & $290(32.5 \%)$ \\
\hline 2012 & 1014 & $289(28.5 \%)$ \\
\hline 2013 & 1309 & $378(28.8 \%)$ \\
\hline 2014 & 1977 & $692(35 \%)$ \\
\hline 2015 & 2345 & $736(31.4 \%)$ \\
\hline
\end{tabular}

Chi square test for comparisons

Comparison of 2010 and 2015

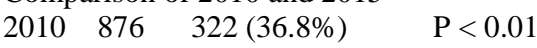

$2015 \quad 2345 \quad 736(31.4 \%)$
Table 2 shows the patient's age, parity, booking status and nature of caesarean sections performed on them. The patient's ages ranged from 16-43 years, with a mean age of 26.9 (3.75) years. The modal age group was 25-29 years in $1,378 / 2,707(50.9 \%)$ patients. The parity ranged from $0-9$, with a mean of 1.67 (standard deviation 0.74 ). Majority, 1684/2,707 (62.2\%), were multipara (para 1-4). A total of $1719 / 2,707(63.5 \%)$ were unbooked patients and $2285 / 2,707(84.4 \%)$ of the surgeries were emergency deliveries.

Table 2: Main characteristics of 2,707 cases of caesarean delivery over a 6-year period (2010-2015).

\begin{tabular}{|c|c|c|c|}
\hline Item & $\begin{array}{l}\mathbf{N}(\%) \\
(\mathbf{N}=2,707)\end{array}$ & Range & Mean $( \pm$ SD $)$ \\
\hline \multicolumn{4}{|l|}{ Age(years) } \\
\hline$\leq 19$ & $27(1 \%)$ & & \\
\hline $20-24$ & $688(25.4 \%)$ & & \\
\hline $25-29$ & $1378(50.9 \%)$ & $16-43$ & $26.7( \pm 3.75)$ \\
\hline $30-34$ & $512(18.9 \%)$ & & \\
\hline$\geq 35$ & $102(3.8 \%)$ & & \\
\hline \multicolumn{4}{|l|}{ Parity } \\
\hline 0 & $961(35.5 \%)$ & & \\
\hline $1-4$ & $1684(62.2 \%)$ & $0-9$ & $1.67( \pm 0.74)$ \\
\hline$\geq 5$ & $62(2.3 \%)$ & & \\
\hline \multicolumn{4}{|c|}{ Booking status } \\
\hline Booked & $988(36.5 \%)$ & & \\
\hline Unbooked & $1719(63.5 \%)$ & & \\
\hline \multicolumn{4}{|c|}{ Nature of CS } \\
\hline Emergency & $2285(84.4 \%)$ & & \\
\hline Elective & $422(15.6 \%)$ & & \\
\hline
\end{tabular}

Table 3: The indications for the caesarean deliveries in 2,707 cases delivered over a 6-year period (2010-2015).

\begin{tabular}{|ll|}
\hline Indications & N $(\%)$ \\
\hline Previous LSCS & $893(33 \%)$ \\
\hline Fetal distress & $709(26.2 \%)$ \\
\hline Breech & $238(8.8 \%)$ \\
\hline Refusal of VBAC & $203(7.5 \%)$ \\
\hline Placenta previa & $157(5.8 \%)$ \\
\hline NPOL & $122(4.5 \%)$ \\
\hline Unclear indications & $125(4.6 \%)$ \\
\hline Multiple gestation & $94(3.5 \%)$ \\
\hline Failed induction & $94(3.5 \%)$ \\
\hline Obstructed labour & $89(3.3 \%)$ \\
\hline IUGR/ Abnormal Doppler & $49(1.8 \%)$ \\
\hline Malpresentation & $41(1.5 \%)$ \\
\hline Scar tenderness & $41(1.5 \%)$ \\
\hline Cephalopelvic disproportion & $41(1.5 \%)$ \\
\hline Previous hysterotomy & $8(0.3 \%)$ \\
\hline Oligohyroamnios & $3(0.1 \%)$ \\
\hline fibroid & $3(0.1 \%)$ \\
\hline
\end{tabular}


Table 3 shows the indications for caesarean delivery. Some patients had multiple indications. Previous caesarean section, the most common indication, was documented in $893 / 2,707(33 \%)$ of the cases, out of which in 203/2,707 (7.5\%) indication of repeat caesarean section was refusal of VBAC. Other major indications were fetal distress, breech presentation, placenta previa, non progress of labour, multiple pregnancy, failed induction, obstructed labour, intrauterine growth retardation with abnormal Doppler findings, malpresentation, cephalpelvic disproportion and scar tenderness. Out of 2,707 caesarean deliveries, 122 (4.6\%) was done due to unclear indications.

\section{DISCUSSION}

Primary caesarean section usually determines the future obstetric course of any woman and therefore should be avoided wherever possible. The caesarean section rate in our study was $32.18 \%$. The rising caesarean section rate is a worldwide phenomenon although WHO states that there is no additional benefit associated with rising caesarean section rate of above $15 \% .^{10}$ In England caesarean section rate was $9 \%$ in 1980 which was raised to $21.3 \%$ in $2000 .^{11,12}$ Haidar $G$ et al from Hyderabad Pakistan and Shamshad from Abotabad reported caesarean section rate as high as $67.7 \%$ and $45.1 \%$ in 2007 respectively. ${ }^{13,14}$

In the present study, most common indication for caesarean section was previous caesarean section (33\%) as in other studies. Lubna Ali from Karachi Pakistan reported repeat caesarean section the commonest indication for caesarean section, similar trends have been found in Northern Greece (30.9\%) by Mersaovdi et al. ${ }^{15,16}$ So the decision for primary caesarean section is important, unless there is clear, compelling and well supported justification for caesarean section, a carefully supervised justified trial of labour is necessary. ${ }^{16,17}$ Trial of scar in singleton pregnancies can be given to reduce the rate of repeated caesarean section as the risk of uterine rupture is low $0.3 \% .^{18}$ Successful vaginal birth after caesarean (VBAC) in grand multiparous does not lead to increased maternal complication. ${ }^{19}$

Second most common indication for caesarean section was fetal distress $(26.2 \%)$. This can be minimized if careful consideration is taken while weighing the risks and options available. Gold standard technique to detect fetal distress is fetal scalp blood $\mathrm{pH}$ estimation which is not performed in our hospital.

Other common indications documented were breech $(8.8 \%)$, placenta previa $(5.8 \%)$, no progress of labour $(4.5 \%)$, multiple gestation $(3.5 \%)$, obstructed labour $(3.3 \%)$, failed induction $(3.5 \%)$ and cephalopelvic disproportion $(1.5 \%)$. In 238 patients $(8.8 \%)$, caesarean section was done due to breech presentation because of lack of skill in providing external cephalic version especially to singleton fetuses with no contraindications to this procedure. Current research suggests that labour induction makes a caesarean section more likely among primigravidas if cervix is unfavourable..$^{20,21}$ Use of partogram helps in early diagnosis of abnormal labour patterns and timely management, antenatal diagnosis of mal presentation and their effective management greatly prevents obstructed labour as well as failed progress. ${ }^{22}$ In $125(4.6 \%)$ patients, indication of caesarean section was unclear.

The majority of caesarean section in this study was of unbooked cases $(63.5 \%)$ and because of an emergency indication $(84.4 \%)$. People do not believe in antenatal care and consider birth as a natural process. They bring women to the hospital only when they are seriously ill and insist on vaginal delivery. ${ }^{23}$ Women of higher socioeconomic status and with higher education are more likely to accept caesarean section as they are able to afford this method of delivery. ${ }^{24}$

It is well documented that caesarean carries much high maternal mortality and morbidity as compared to vaginal delivery even though caesarean section is being performed for indications such as fetal distress; perinatal mortality continues to be very high among caesarean deliveries. $^{25}$

The high caesarean section rate in our study was because most of these patients are referred to this teaching hospital that have one or the other risk factors and who already had a trial of labour somewhere else. So, the caesarean section rate was obviously high in these high risk and unbooked cases.

\section{CONCLUSION}

The caesarean section rate in our study was $32.18 \%$, because mostly referred cases after initial trial of dais, lady health visitors and general practitioners in private hospitals were received. Common indications of caesarean section observed in this study were previous caesarean section (33\%). Majority of patients who underwent caesarean section were unbooked.

Measures recommended to reduce caesarean section are as follows:

- Proper antenatal care and counseling regarding the planned hospital delivery.

- Proper diagnosis of labour.

- Partogram should be maintained for good monitoring of progress of labour especially in patients with previous one caesarean section.

- Good analgesia and proper fetal monitoring during labour.

- Avoiding undue inductions of labour.

- Trial of VBAC should be encouraged in appropriate cases.

- Expertise in external cephalic version and vaginal breech delivery in good selected cases. 
- Proper training of traditional birth attendants and lady health visitors, effective working of referral chain and time demanded health policies.

\section{ACKNOWLEDGMENTS}

We wish to acknowledge the management for providing the environment for this study.

\section{Funding: No funding sources}

Conflict of interest: None declared

Ethical approval: The study was approved by the Institutional Ethics Committee

\section{REFERENCES}

1. Souza JP, Gulmezoglu A, Lumbiganon P, et al. WHO Global Survey on Maternal and Perinatal Health Research Group Caesarean Section without medical indications is associated with an increased risk of adverse short-term maternal outcomes: the 2004-2008 WHO Global Survey on Maternal and Perinatal Health. BMC Med. 2010;8(1):71.

2. Farine D, Shepherd D. Classification of caesarean sections in Canada: the modified Robson criteria, SOGC Committee Opinion. J Obstet Gynecol Can. 2012;34(10):976-9.

3. De Padua KS, OSIS MJD, Faunder A, Barbosa AH, Fitho OBM. Factors associated with caesarean section in Brazilian Hospitals. Rev Saude Publication. 2010;44(1).

4. Chalmers B. WHO appropriate technology for birth revisited. Br J Obstet Gynecol. 1992;99:709-10.

5. Betran AP, Mepaldim, Lauer JA, Bingshum W, Thomas J, Vanlook P, et al. Rates of caesarean section: Analysis and perinatal epidemiology. 2007;21:98-113.

6. Geida AD, Audu BM, Kawuwa BM, Obed JY. Rising trend and indications of caesarean section at the university of Maiduguri teaching hospital, Nigeria. Annals of African Medicine. 2009;8:127-32.

7. Naymi RS, Rehan N. Prevalence and determinants of caesarean section in a teaching hospital of Pakistan. Journal of Obstetric and Gynaecology. 2000;20:47983.

8. Sunday-Aleoye I, Kalu CA. Pregnant Nigerian women's view of caesarean section. Nigerian Journal of clinical practice. $2011 ; 14: 276-9$.

9. Penna L, Arulkuraman S. Caesarean section for nonmedical reasons. International Journal of Gynecology and Obstetrics. 2003;82:399-409.
10. Belizan JM, Althabe F, Barros FC. Rates and implications of caesarean sections in Latin America. BMJ: 1999;319:1397-402.

11. Thomas J, paranjothy $\mathrm{S}$. The national sentinel caesarean section audit report. RCOG press. 2001 Nov: NEJMc090206.

12. Treffers PE, Pel M. The rising trend for caesarean birth. BMJ: 1993;307:1017-8.

13. Haider G, Zehra N, Munir AA, Haider A. Frequency and indication of caesarean section in a tertiary care hospital. Pak J Med Sci. 2009;25(5):791-6.

14. Shamshad. Factors leading to increased caesarean section rate. Gomal J Med Sci. 2008:(1):1-5.

15. Ali L, Tayyab S, Fouzia P. Caesarean c-section rate, current trends. J Surg Pak. 2007;12(2):64-6.

16. Dinas K. Current caesarean section delivery rates and indications in major public hospital in Northern Greece. Aust N Z J Obstet Gynaecol. 2008;48(2):142-6.

17. Chaudhary SM, Ayaz A. Efforts to reduce Caesarean section Rate. J Surg Pakistan. 2003;8(1):25-7.

18. Spong CY, Lanndon MR. Risk of uterine rupture and adverse perinatal outcome at term after caesarean delivery. Obstet Gynaecol. 2007;110(4):801-7.

19. Kugler E, Shoham-Vardi I. The safety of a trial of Labour after caesarean section in a grand multiparous population. Arch Gynaecol Obstet. 2008;277:339-49.

20. Rayburn WF. Minimizing the risk from elective induction of labour. J Reprod Med. 2007;52:671-6.

21. Declercq E, Menacker F. Maternal risk profiles and primary caesarean rate in United States. Am J public health. 2006;96:867-72.

22. Friedman EA. The labour curve. Clinical Perinatology. 1981;8:5.

23. Tampakoudis P, Assimakopoulos E, Grimbizis G, Zafrakas M, Tampakoudis G, Mantalenakis S, et al. Caesarean section rates and indication in Greece: data from a 24 year period in a teaching hospital. Clin Exp Obstet Gynaecol. 2004;31(4):289-92.

24. Kim ES, Byun YC, Lee SH. Astudy on socio economic factor related to caesarean section in Korea. Bogeon Sahoe Nonjib. 1991;11(2):19-35.

25. Bhasin SK, Rajoura OP, Sharma AK, Meyha M, Gupta N, Kumar S, etr al. A high prevalence of Caesarean Section in East Delhi. Indian Journal of Community Medicine. 2007;32(3):222-4.

Cite this article as: Saxena N, Sharma B, Gupta V, Negi KS. A six year appraisal of caesarean delivery at a teaching hospital in Uttarakhand. Int J Reprod Contracept Obstet Gynecol 2016;5:4369-72. 